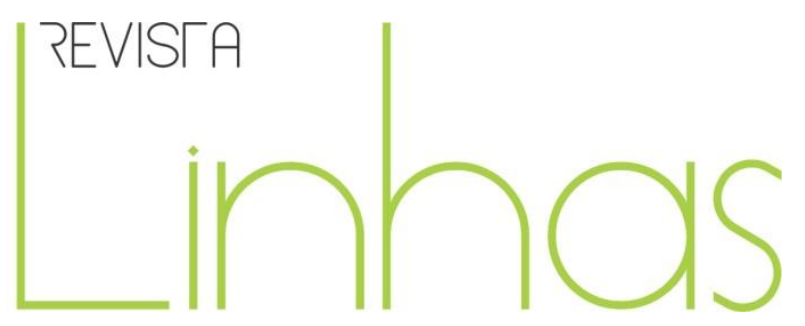

\title{
Usos de las Tecnologías de la información y la comunicación por docentes de México, España y Brasil ${ }^{1}$
}

\begin{abstract}
Resumen
El propósito del artículo es analizar los principales usos de las Tecnologías de la información y la comunicación (TIC) por docentes de la educación superior de México, España y Brasil. La estrategia metodológica empleada es cualitativa. Se presentan los resultados de un estudio exploratorio, obtenidos por medio de un cuestionario a docentes, que muestran el uso de TIC en los momentos preactivos, interactivos y evaluativos de la enseñanza. Se concluye que no hay resistencias al utilizar las TIC, pero ni siempre se las aprovechan para dialogar con ideas establecidas o bien transformar la enseñanza, enmascarando, en unos casos, prácticas tradicionales.
\end{abstract}

Palabras clave: Tecnologías de la Información y la Comunicación. Práctica Pedagógica. Educación Superior. Innovación.
Rogério Arruda

Universidade Federal do Rio

Grande - FURG - Rio Grande/RS Brasil

rogerio.arruda@hotmail.com

\section{Martha Prata-Linhares}

Universidade Federal do

Triângulo Mineiro - UFTM -

Uberaba/MG - Brasil

martha.prata@uftm.edu.br

Joaquín Paredes

Universidad Autónoma de

Madrid - España

joaquin.paredes@uam.es

\section{Para citar este artigo:}

ARRUDA, Rogério; PRATA-LINHARES, Martha; PAREDES, Joaquín. Usos de las Tecnologías de la información y la comunicación por docentes de México, España y Brasil. Revista Linhas. Florianópolis, v. 20, n. 43, p. 78-101, maio/ago. 2019.

DOI: $10.5965 / 1984723820432019078$

http://dx.doi.org/10.5965/1984723820432019078

\footnotetext{
${ }^{1}$ Esta pesquisa recebeu apoio financeiro da Coordenação de Aperfeiçoamento de Pessoal de Nível Superior (CAPES), do Brasil.
} 


\section{Uses of information and Uso de Tecnologias da communication technologies Informação e Comunicação by teachers from Mexico, por professores do México, Spain and Brazil \\ Espanha e Brasil}

\begin{abstract}
The purpose of this article is to analyze the primary uses of Information and Communication Technologies (ICT) by higher education teachers in Mexico, Spain, and Brazil. The methodological strategy used is qualitative. We present the results of an exploratory study, obtained through a questionnaire to teachers, showing the use of ICT in the pre-active, interactive and evaluative moments of teaching. It is concluded that there is no resistance when using ICT, but ICTs are not always used to dialogue with established ideas or to transform teaching, in some cases masking traditional practices.
\end{abstract}

Keywords: Information and Communication Technologies. Pedagogical Practice. Higher Education. Innovation.

\begin{abstract}
Resumo
O objetivo deste artigo é analisar os principais usos das Tecnologias de Informação e Comunicação (TIC) por professores do ensino superior no México, na Espanha e no Brasil. A estratégia metodológica utilizada é qualitativa. Apresentamos os resultados de um estudo exploratório, obtido através de um questionário aos professores, mostrando o uso das TIC nos momentos pré-ativos, interativos e avaliativos do ensino. Conclui-se que não há resistência na utilização das TIC, mas que nem sempre elas dialogam com as ideias estabelecidas ou transformam o ensino, em alguns casos mascarando práticas tradicionais.
\end{abstract}

Palavras-chave: Tecnologias da Informação e Comunicação. Prática Pedagógica. Ensino Superior. Inovação. 


\section{Introducción}

El presente artículo parte de un proyecto de investigación que se planteó como propósito identificar y comprender las principales innovaciones y cambios pedagógicos en la práctica docente con el uso de las Tecnologías de la Información y la Comunicación (TIC) en cursos de licenciatura de Instituciones de Educación Superior de México, España y Brasil. El problema principal que orientó la investigación es el siguiente: ¿cuáles son las principales características de las prácticas docentes innovadoras en instituciones educativas de distintos países? Se desarrolló la investigación con base en el supuesto del rápido desarrollo de la tecnología. Este escenario ha ampliado las formas de interacción entre un usuario y el medio tecnológico, generando un mayor número de posibilidades para la búsqueda de la información y la comunicación, aunque la competencia digital puede abarcar otros procesos, como reelaborar la información y, así, crear contenidos nuevos o bien resolver problemas. Así que, por una parte, las TIC pueden constituirse en un valioso instrumento para ser constantemente incorporado a las actividades académicas, pues con sus potencialidades, alcances e innovaciones ofrecen nuevos soportes a los procesos de enseñanza y aprendizaje, incluso generando nuevos espacios de socialización pedagógica. Por otra parte, del mismo modo que pueden ser extremamente relevantes a la educación, puede que no añadan necesariamente nada de nuevo a la enseñanza (PAREDES, 2013; SANCHO, 2013; SANCHO \& ALONSO, 2012), en el caso de que los docentes decidan no desarrollar nuevas actividades con ellas, haciendo que la innovación que las acompaña se pierda o se transforme en rutina.

En este artículo se analizará específicamente lo referente a uno de los hallazgos del estudio, que trata de los principales usos de las TIC en la práctica de los docentes de esos países. Así que el interrogante específico sobre el cual se trabajará aquí es: ¿Cuáles son y qué revelan los principales usos de las TIC en la práctica de esos docentes de Educación Superior? 


\section{Marco Conceptual}

Las cuestiones que hacen referencia al uso de las TIC en la enseñanza y la práctica docente han sido objeto de varios estudios (por ejemplo: SILVA, 2012; TEJADA, 2008; PAREDES, 2009; BRIJALDO-RODRÍGUEZ \& SABOGAL-MODERA, 2015; GONZÁLES, 2007; SOARES-LEITE \& NASCIMENTO-RIBEIRO, 2012; PAREDES \& ARRUDA, 2012; CABERO, 2006; MORAN, 2008). Estos estudios de modo general apuntan que, además de la importancia de las TIC para la educación -por ejemplo, cuando se usan para comunicar y transmitir información o para proponer actividades que favorezcan la construcción de conocimiento y el papel activo de los estudiantes, el uso de los recursos tecnológicos en el proceso educativo trae consigo la necesidad de algunas adecuaciones que van a exigir el desarrollo de nuevas competencias y actitudes de docentes y estudiantes.

Entre los distintos aspectos presentes en estos estudios, se destacan las condiciones de éxito (o no) de la integración de las TIC en el proceso de enseñanza y aprendizaje. Sobre ello, surge el siguiente interrogante: ¿Serán los recursos tecnológicos realmente una ventaja para la actividad de docentes y estudiantes, propiciando la innovación pedagógica, o van a entorpecer el estudio? Se entiende que esa cuestión tiene que ver con la postura de docentes y estudiantes ante las TIC, como la concordancia o el rechazo al uso de esos recursos. Rechazo que puede tener origen en conflictos de orden personal, por ejemplo, en relación con las creencias y conductas del propio sujetodocente, o institucional, que tiene que ver con los valores conceptuales y estructurales de una institución.

De este modo, se ha observado que la apropiación de los recursos tecnológicos por parte de los docentes no es uniforme, ya que las TIC se presentan de manera diferente a cada persona, haciendo que algunos las utilicen sólo esporádicamente y de una manera no comprometida, sea porque no están preparados para su utilización o porque no conocen sus alcances y beneficios, mientras que otros hacen un uso más regular, de modo avanzado, sacando mayor aprovechamiento de las posibilidades educativas y comunicativas que ofrecen. En este sentido, la consecución de los objetivos 
educativos mediante el uso de las TIC tiene implicaciones directas en la actitud del docente a estos recursos tecnológicos.

Otro aspecto que también tiene una fuerte presencia en las discusiones de esta investigación se refiere a la cuestión de la motivación provocada por la introducción de estas tecnologías en el proceso de enseñanza y aprendizaje. El tema de la relación entre las TIC y la motivación, teniendo en cuenta el contexto de la formación docente, ha sido estudiado por varios autores (por ejemplo: ALONSO-TAPIA, 2005; HENDRIKS, 1999; COX, PRESTON \& COX, 1999; GARCÍA, 2002; KARSENTI \& LIRA, 2011; TEJEDOR, GARCÍAVALCÁRCEL \& PRADA, 2009). Los principales aportes de estos estudios indican que hay una serie de factores que pueden contribuir a la motivación de las personas para utilizar TIC. Los principales son: las creencias en el valor de las TIC para el aprendizaje y la enseñanza; las actitudes de los sujetos ante las TIC; la percepción de competencia para utilizarlas; las dificultades del uso; y los recursos disponibles.

En general, estos autores están de acuerdo en que hay una visión optimista sobre la integración y el uso de las TIC en la enseñanza, ya que consideran como aspectos de motivación, por ejemplo, la posibilidad de hacer clases más interesantes, de mejorar la presentación de materiales de enseñanza; un mayor intercambio de conocimientos mediante la reducción de las barreras temporales y espaciales; la autonomía; y la facilidad de acceso a la información. Sin embargo, hay otros autores que no son tan optimistas en una visión unidimensional (la infraestructura disponible, al igual que las TIC) en los procesos de cambio en la educación, y que hay nuevos problemas asociados con ella, tales como los cambios en la metodología practicada, la participación de los estudiantes o la formación específica de los docentes (PAREDES \& ARRUDA, 2012).

La integración de las TIC en la práctica docente, asociada a la motivación para su uso, puede constituir un factor para desencadenar una práctica innovadora. Un concepto inicial define la innovación como una idea, una práctica o un objeto que es percibido como nuevo por un individuo (ROGERS, 1983), y las TIC pueden ayudar a ello. Sin embargo, nuevos estudios han demostrado que el análisis de una innovación requiere enfoques más densos, destacando el creciente número de factores que influyen directamente en estos procesos (MONTERO \& GEWERC, 2010); es decir, es esencial tener 
en cuenta, en un análisis actual sobre este tema, al menos, los siguientes aspectos: a) geográfico (ubicación de la institución); b) institucional (la estructura, la organización, la cultura y la política educativa de la institución); c) personal (la propia formación docente, creencias teóricas acerca de la enseñanza, la postura sobre el uso de las TIC en la enseñanza, motivación, etc.); y d) instrumental (con respecto a los avances de las potencialidades y aplicabilidades de los recursos tecnológicos).

Añadiendo nuevos enfoques a las primeras ideas de Everett Rogers (1983), un sentido más descriptivo se refiere a dos tipos principales de innovación, la incremental (o sostenida) y la disruptiva. Acerca de la innovación incremental, su base es introducir mejoras en los productos, procesos, organizaciones y sistemas sociales existentes (FIGUEIREDO, 2011). Con respecto a la innovación disruptiva, se señala el hecho de que emergen de forma exploratoria, y las mayores oportunidades para innovar no tratan de mejorar lo que ya existe, sino que crean soluciones para las necesidades no satisfechas (CHRISTENSEN, 2012).

En otros estudios consultados (por ejemplo: MARTíNEZ \& CORREA, 2010; GALLEGO, 2005), el concepto de innovación tiene que ver con cuestiones relacionadas con la mejora y el logro del aprendizaje. Para estos autores, la innovación está presente cuando se le da la oportunidad de que el aprendizaje (con el apoyo de las TIC) salga de las paredes de la escuela, lo que permite conexiones significativas con la realidad extraescolar, provocando efectos positivos en la educación de los estudiantes. Esto también se hizo eco de las ideas defendidas por otros autores, que añaden que dicha formación debe preparar, además de estudiantes, ciudadanos responsables, solidarios y dinámicos, capaces de hacer una "lectura de mundo" más amplia, preparados para adaptarse a las nuevas situaciones y promover la creatividad y la calidad personal y social (SANCHO, BOSCO, ALONSO \& SÁNCHEZ, 2015).

Ampliando los horizontes de "más allá de las paredes de la escuela”, hay la opinión de que la innovación se caracteriza por la idea de cambiar algo, pero este cambio debe convertirse en una propuesta intencional de la escuela, que tenga en cuenta la comunidad en la que opera, con la intención de dar respuestas a sus necesidades reales, internas, y también sus alrededores (MONTERO \& GEWERC, 2010). 
Por otro lado, hay estudios en los que existe la vinculación del concepto de innovación con las estrategias adoptadas en el proceso de enseñanza, por ejemplo, integrando varios elementos complejos, incluyendo la necesidad de pensar estrategias que permiten a los sujetos familiarizarse con la propia innovación, facilitando, de este modo, el desarrollo de habilidades cognitivas de alto nivel. Esto es debido al hecho de que hay docentes que, incluso con el uso de los recursos digitales, reproducen prácticas pedagógicas tradicionales (OROZCO, 2007). Es, por lo tanto, un proceso de "negociación” con estos docentes con el fin de crear oportunidades para que puedan superar tales prácticas, y construyan formatos verdaderamente innovadores.

Otros sostienen que el concepto de innovación está relacionado con la integración de las TIC en el currículo. Entre ellos, hay los que afirman que la adopción de prácticas innovadoras se basa en un paradigma de enseñanza-aprendizaje que hace de la flexibilidad curricular el desarrollo de habilidades y la articulación curricular sus principales fortalezas (ALVES, MORGADO, LEMOS, CRUZ \& OLIVEIRA, 2011). También se pone de relieve la necesidad de promover transformaciones curriculares para superar los límites impuestos por los currículos tradicionales y así avanzar en las prácticas de enseñanza innovadoras (PRATA-LINHARES \& GAETA, 2016). Y además de los cambios en el currículo, la innovación implica también cambios en las formas de ver, pensar, organizar y articular disciplinas (SALINAS, 2009). José Tejada (2008) está de acuerdo con el hecho de que la innovación requiere cambios en los elementos curriculares, en el sentido de que tales cambios deben basarse en un objetivo común orientado a la mejora y el crecimiento tanto personal como institucional. Por otra parte, recomienda cambios internos y cualitativos también en los procesos educativos y sus contextos inmediatos, con criterios objetivos.

Otro aspecto que se encuentra en la revisión de la literatura busca articular el concepto de innovación al deseo personal y a la relación entre el docente y el estudiante, en el sentido de que el deseo y la actitud de los docentes deben moverse para tratar de mejorar sus prácticas de enseñanza con el fin de proporcionar una mejor educación para sus estudiantes (MARTíNEZ, 2008). Hay también la vinculación del concepto de innovación a la relación entre el docente y el alumno y entre éstos y la construcción del conocimiento en el proceso educativo, con el argumento de que la innovación 
pedagógica no sucede por el simple hecho de ir a utilizar las TIC en las aulas (CORREA, 2010). Además, también es imprescindible para la innovación educativa el cuestionamiento acerca de lo naturalizado y la reflexión de los sujetos del proceso de enseñanza-aprendizaje, lo que permite repensar los desafíos y construir otra mirada a la realidad (CORREA, FERNÁNDEZ, GUTIÉRREZ-CABELLO, LOSADA \& OCHOA-AIZPURUA, 2015).

Sin embargo, no se puede olvidar de la presencia de la innovación con el uso de las TIC en la dinámica del trabajo colaborativo en red, que proporciona a la educación y a los procesos de formación nuevos métodos de aprendizaje colaborativos con impacto en el desarrollo de los procesos de interacción (MELARÉ, NEVES, SEABRA, MOREIRA \& HENRIQUES, 2011). Las redes sociales y sus nuevas dinámicas, por ejemplo, representan un potencial pedagógico cuyas investigaciones deben profundizarse.

\section{Metodología}

Se realizó un estudio exploratorio cualitativo para conocer las percepciones de los sujetos de la investigación acerca de las características de las prácticas docentes innovadoras con el uso de las TIC. El estudio exploratorio se lleva a cabo especialmente cuando el tema elegido está poco explorado y se hace difícil formular hipótesis precisas sobre ello (GIL, 1999); y, con eso, también se busca definir proposiciones para orientar estudios posteriores (YIN, 2014). En el caso aquí presentado, la dinamicidad del desarrollo de los recursos tecnológicos y los rápidos avances de sus usos en la educación avalan la opción por este tipo de estudio.

El enfoque cualitativo se adoptó debido a los objetivos analíticos de la investigación, en el sentido de permitir un diseño flexible que posibilitara articular las percepciones de sujetos de tres países distintos, cada uno con sus particularidades.

El muestreo adoptado fue por conveniencia y de tipo de probabilidad no intencional, que trata de seleccionar un subconjunto de una población determinada (ALAMINOS \& CASTEJÓN, 2006). Tal elección es considerada adecuada para su uso en 
una investigación de enfoque cualitativo, pues presenta interés intrínseco para reflejar realidades múltiples o descubrir significados (MARTíN-CRESPO \& SALAMANCA, 2007).

En el diseño metodológico de la investigación se realizaron dos fases: (1) la recogida de datos de referencia por medio de cuestionario (cuya versión definitiva fue preparada tras la aplicación de un piloto) a distancia; y (2) el análisis de datos, basado en el Análisis de Contenido (BARDIN, 2011). Como se trata de una investigación sobre formación docente, se eligió como sujetos de investigación docentes de algunos cursos de licenciatura de la Escuela Normal de Tlalnepantla (México), de la Universidad Autónoma de Madrid (España), y de la Universidad Federal do Triângulo Mineiro (Brasil). Después del ajuste sobre la cuestión de los sujetos, el siguiente paso fue ponerse en contacto con los directores de los departamentos de los cursos involucrados para la presentación de la propuesta de investigación y solicitarles permiso para contactar con los docentes. Con la aprobación de los directores se inició la primera fase, de recolección de datos. Para ello, se hicieron contactos individuales con los docentes de los cursos involucrados en la investigación y se invitó a todos ellos a que participaran contestando al cuestionario (Cuadro 1) por medio del correo electrónico. En el mensaje enviado a los docentes también se estableció un plazo para que ellos devolvieran el cuestionario completado y el consentimiento para el uso de los datos, así como se les indicó que el tratamiento de los datos seguiría un protocolo de confidencialidad.

Cuadro 1. Cuestionario presentado a los sujetos de la investigación

1. ¿Utiliza usted algún recurso de las TIC como apoyo a su práctica docente?

2. En el caso de utilizar las TIC, haga un comentario sobre los motivos que le llevaron a incorporar esos recursos en su práctica docente. (Si no utiliza las TIC, ¿por qué motivos?)

3. ¿En qué momentos utiliza usted los recursos de las TIC en el proceso de enseñanza y aprendizaje con más frecuencia?

4. ¿Cuál es su percepción de innovaciones y cambios pedagógicos derivados de la utilización de las TIC en su práctica docente?

5. Teniendo en cuenta el conjunto de actividades llevadas a cabo por los docentes en la enseñanza universitaria, ¿qué papel tiene la creatividad en los procesos de innovación y cambio de la realidad educativa?

6. ¿Hay otros comentarios que desea hacer?

Fuente: elaboración propia. 
El número de docentes contactado fue de un total de 122, y el de docentes que efectivamente respondieron y devolvieron el cuestionario y el consentimiento para utilización de los datos fue de un total de 27 participantes.

Tabla 1. Conformación de la muestra

\begin{tabular}{ccccc}
\hline Docentes & ENT/México & UAM/España & UFTM/Brasil & Total \\
\hline Total contactado & 17 & 40 & 65 & 122 \\
\hline Total participante & 10 & 08 & 09 & 27 \\
\hline
\end{tabular}

Fuente: elaboración propia.

Para mantener la confidencialidad, en el próximo apartado, donde serán presentados y discutidos los resultados, los nombres de los participantes serán identificados por códigos que fueron asignados de forma aleatoria. Los códigos son los siguientes:

- Códigos para los docentes de México: DM1 a DM10

- Códigos para los docentes de España: DE1 a DE8

- Códigos para los docentes de Brasil: DB1 a DB9

En la segunda fase se realizó el análisis e interpretación de los datos basados en el Análisis de Contenido, en que se puede demostrar que la lectura particular del observador es válida y generalizable, ayudando a aclarar significados susceptibles de elementos que conducen a una descripción de los mecanismos que a priori no se tiene un entendimiento (BARDIN, 2011). Además, para entender las situaciones de la vida cotidiana es esencial tener en cuenta el entorno en el que existen este tipo de situaciones, así como el núcleo de ciertos espacios de interacción personal e institucional, dado que están mediados por las modalidades técnicas de construcción y transmisión de mensajes, cada vez más complejas hoy día. Esta situación refleja con precisión el tema investigado en este 
estudio, ya que se centra en los diferentes tipos de usos de las TIC por parte de los sujetos que participan en el proceso de enseñanza y aprendizaje.

\section{Resultados y discusión}

Los datos obtenidos de los sujetos de las instituciones participantes de esta investigación son discutidos con el fin de comprender las innovaciones y cambios pedagógicos que están sucediendo en la práctica de la enseñanza con el uso de las TIC. Como se anuncia en la introducción, en este artículo se abordará una de las cuatro categorías que surgieron a partir del análisis de datos ${ }^{2}$ : los principales usos de las TIC en la práctica docente.

Uno de los interrogantes motivadores del estudio fue: ¿Cuáles son las posibilidades de encontrar, en la actualidad, un docente que no utiliza las TIC en su práctica? Así que, cuando se les preguntó si utilizan las TIC en sus prácticas, los 27 participantes respondieron que sí, ya sea en las actividades realizadas en la preparación de clase, durante la clase, o en tiempos posteriores a la clase. La utilización se produce en diferentes momentos didácticos (Cuadro 2). Por lo tanto, se considera que el uso de las TIC en la enseñanza es una práctica común entre los sujetos de investigación.

Cuadro 2. Panorama general sobre los principales usos de las TIC

\begin{tabular}{|c|l|}
\hline Momentos en que se aplica & \multicolumn{1}{c|}{ Principales usos } \\
\hline \multirow{3}{*}{ Preactivos } & - Buscar información para utilización en clase \\
& - Disponer material digital para los estudiantes \\
& - Comunicarse con los alumnos (e-mail y redes sociales) \\
& - Recolectar informaciones sobre el grupo de alumnos \\
& - Presentar información del curso a los estudiantes \\
\hline
\end{tabular}

\footnotetext{
${ }^{2}$ Además de la categoría aquí analizada, las otras tres que emergieron en el análisis del estudio son: "Las motivaciones para incorporar las TIC a la práctica docente"; "La importancia de la creatividad para promover innovaciones pedagógicas"; y "La percepción del docente sobre el uso innovador de las TIC en su práctica".
} 


\begin{tabular}{|l|l|}
\hline & $\begin{array}{l}\text { - Indicar sitios de Internet para consulta } \\
\text { - Organizar la plataforma digital de aprendizaje }\end{array}$ \\
\hline Interactivos & $\begin{array}{l}\text { - Proyección de videos y otros recursos didácticos } \\
\text { - Simulaciones de procesos } \\
\text { - Búsqueda de información } \\
\text { - Estimulación de la generación de ideas } \\
\text { - Realización de trabajos colaborativos } \\
\text { - Alternancia de las estrategias didácticas } \\
\text { Evaluativos }\end{array}$ \\
\hline & - Uso del Skype (para clases a distancia) \\
\hline & - Exploración de gráficos de funciones y modelos en 3D \\
\hline & - Resolver dudas de los estudiantes (foros y chats) \\
- Revisar los trabajos & - Reorganizar la plataforma digital de aprendizaje \\
\hline
\end{tabular}

Fuente: elaboración propia.

Obviamente, la práctica docente no es uniforme, con la variación en las formas de integración y los tipos de uso que se hace de las TIC, que en consecuencia también influye en los resultados obtenidos con el uso de los recursos tecnológicos. En esta perspectiva, uno de los aspectos que guiará la discusión de esta categoría de análisis se refiere al principal uso pedagógico de las TIC, que también puede reflejar la posición del docente ante dichos recursos. Para ayudar en esta comprensión, hay que tener en cuenta que, al igual que existen variaciones en las actitudes de los involucrados en el proceso educativo con respecto al uso de los recursos, las TIC se presentan de diferentes maneras a ellos, teniendo en cuenta las diferentes necesidades, creencias y actitudes de cada uno, lo que permite diversas formas de acción. Un ejemplo sobre ello puede ser observado en la Figura 1. 
Figura 1. Momentos en que se utilizan las TIC en la práctica docente (por países)

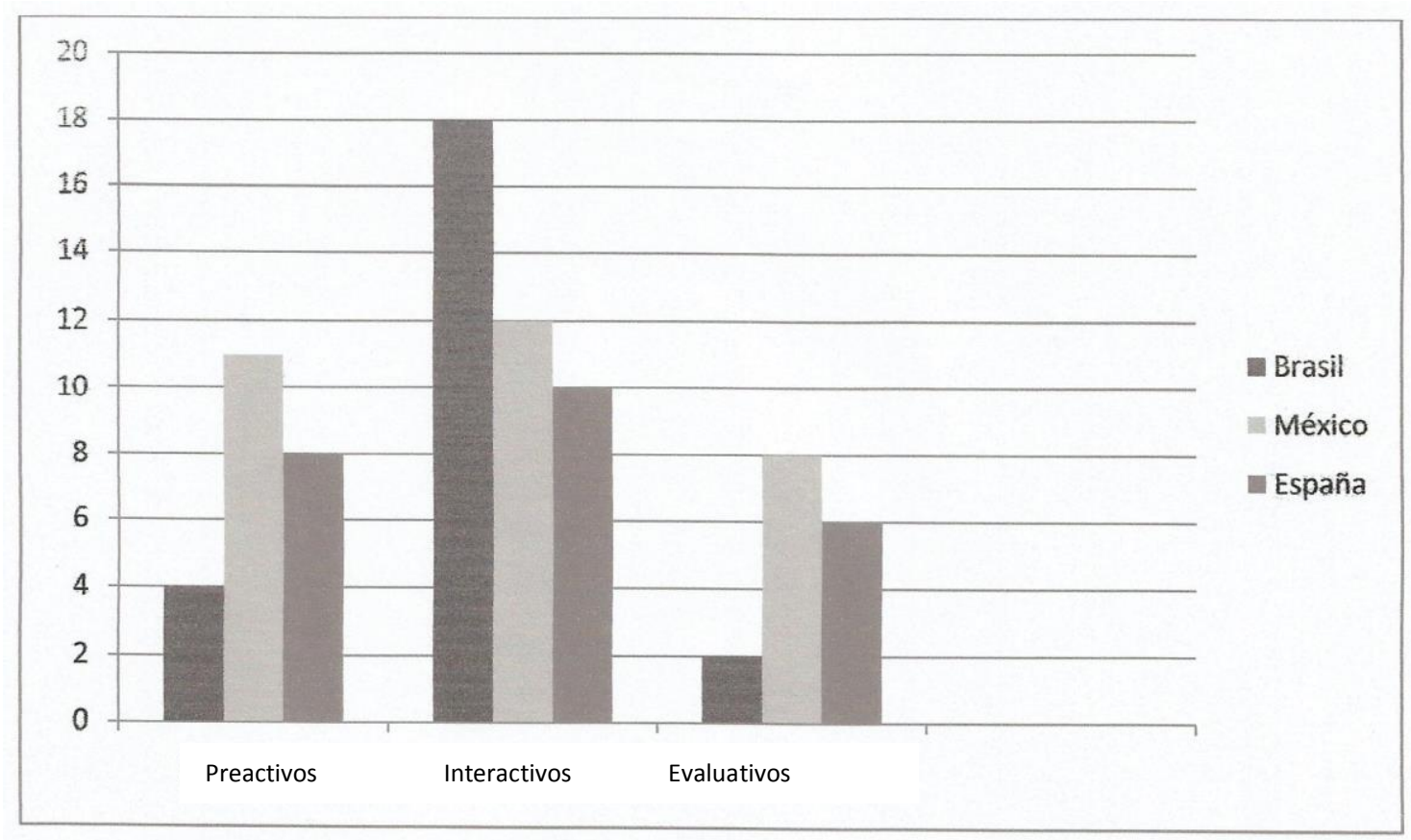

Fuente: elaboración propia.

En la conformación de un panorama general sobre la utilización de las TIC en la práctica docente, se nota cierto equilibrio entre las acciones de los participantes de México y España tanto en los momentos preactivos como en los interactivos y evaluativos de la enseñanza. Por otra parte, los datos sugieren que los participantes de Brasil dan más énfasis al uso de los recursos tecnológicos en el momento interactivo.

A continuación, se presentarán algunas opiniones de los sujetos, seguido de un análisis con el apoyo de la teoría que fundamenta este estudio, para completar una comprensión del fenómeno estudiado.

La primera opinión es la del participante DB6. Sobre los principales usos que hacen de las TIC, dice que:

En primer lugar, en la explicación de las cuestiones relacionadas con la educación, a través de temas. A veces utilizo imágenes o vídeos provocativos en el inicio de la explicación. En algunas asignaturas, utilizo simulaciones por ordenador o applets de experimentos, y situaciones físicas sobre conceptos. (Participante DB6) 
Este testimonio refleja principalmente el momento interactivo de la práctica docente con en el uso de las TIC. Además, cabe destacar dos aspectos en su opinión. El primero, que se refiere a su uso de la tecnología, hace referencia a la comprensión de que las TIC se utilizan en la preparación y ejecución de la clase, como el apoyo técnico a la práctica docente, teniendo en cuenta la explotación del potencial educativo y comunicacional de los recursos (por medio de imágenes, videos, aplicativos o simulaciones). Por lo tanto, se identifica la actitud favorable a la utilización de los recursos tecnológicos. Sin embargo, esto no es garantía de que se ha superado la práctica de la enseñanza tradicional, porque incluso con la incorporación de tecnologías, un docente puede desempeñar un papel en que utiliza las TIC como instrumentos de refuerzo de la enseñanza tradicional, centrado en él mismo (OROZCO, 2007; MORAN, 2008).

El segundo aspecto es justamente sobre el tipo de papel docente que el participante desempeña. Cuando comenta que utiliza la introducción de imágenes o videos "provocativos" al principio de la explicación, revela el papel de mediador (o, al menos, la búsqueda del mismo), ya que, al provocar a sus estudiantes, demuestra su intención de abrir un espacio para el debate académico, dándoles también el protagonismo en el proceso de enseñanza-aprendizaje (GISBERT, CABERO \& LLORENTE, 2007).

Otra posición sobre los principales usos de las TIC es la del participante DE4. Según él, utiliza las TIC en varios momentos:

Antes de empezar el curso dando publicidad a mi percepción sobre la materia, al comenzar el curso cuando recojo información sobre el grupo, durante el curso para presentar información, dialogar con el grupo, recoger sus ideas, construir conocimiento juntos, al final del curso para evaluar su trabajo y el del curso y para reflexionar sobre cómo ha sido. (Participante DE4).

Los momentos preactivos, interactivos y evaluativos están presentes en este testimonio, que también permite identificar una actitud muy favorable para el uso de las TIC. Además, se percibe que el sujeto DE4 busca con este uso ir más allá de modos 
convencionales o tradicionales del quehacer pedagógico, ya que en la medida que promueve la integración de tales recursos a su práctica amplía las opciones metodológicas y didácticas (CABERO, 2006). También puede darse cuenta de la función mediadora que el sujeto DE4 adopta en el proceso educativo, dada su propuesta de diálogo con el grupo, así como el deseo de participar junto con los estudiantes de la construcción del conocimiento, lo que supone una visión ampliada de la competencia digital que manejan los docentes y los estudiantes. Otro aspecto relevante en su comentario es el hecho de que el uso de las TIC va más allá del apoyo técnico a las estrategias de enseñanza, y también se utiliza para reflexionar sobre el proceso de enseñanza desarrollado. Esta reflexión es un importante apoyo para que la incorporación de las TIC en la práctica docente se lleve a cabo de la forma más natural y más consciente posible, evitando así el uso "artificial" de estos recursos, en los que se utilizan de manera excesiva e indiscriminada, con una preocupación estética, más que de contenido.

El participante DM6 afirma que sus principales usos de las TIC tienen lugar durante todo el año escolar, usando:

[...] WhatsApp y correo electrónico para información urgente; Facebook para trabajar normalmente, ya que allí se publican los archivos, trabajos, investigación de los estudiantes, productos, presentaciones y documentos de texto para trabajar, además de los cursos en la plataforma DGESPE -Dirección General de Educación Superior para Profesionales de la Educación-. (Participante DM6)

Se puede decir que este sujeto también tiene una actitud favorable a la utilización de las TIC en la práctica docente, incluyendo la realización de diversas maneras, especialmente en los momentos preactivos e interactivos. Es de destacar el uso de las redes sociales y plataformas en Entornos Virtuales de Aprendizaje (EVA) por el sujeto para desarrollar la mayor parte de sus actividades del proceso de enseñanza. Las redes sociales han favorecido una nueva dinámica en la relación entre los usuarios y de estos con la clase, lo que facilita el intercambio y la creación de contenido y promueve así la interacción. Esto, sin embargo, requiere nuevas habilidades para seleccionar, procesar y 
(re)interpretar la información, lo que es un nuevo potencial pedagógico para ser explorado.

Sobre la tendencia a utilizar los EVA, ésta se centra en nuevas percepciones y formatos de diseño de educación abierta (en línea), destacando su estructura y las implicaciones para la práctica pedagógica autónoma (MELARÉ et al., 2011).

Otra opinión sobre los principales tipos de uso que hace de las TIC es la del participante DB5, que dice que las TIC son esenciales porque

las asignaturas del área de enseñanza bajo mi responsabilidad tienen una gran carga de trabajo a distancia y actividad como una práctica curricular. Toda esta carga de trabajo, la desarrollo con el uso de las TIC, utilizando Moodle, Facebook, Skype, TEDx, YouTube, WIX, etc. (Participante DB5)

Este sujeto hace hincapié en la importancia del uso de las TIC asociado con actividades que ejerce en la enseñanza a distancia (EAD), en el caso, en los tres momentos de la práctica (preactivos, interactivos y evaluativos). No hay duda de que las TIC han reconfigurado los procesos de enseñanza y, en este caso, en la modalidad a distancia, cambiando las metodologías y didácticas empleadas de acuerdo con las características de este tipo de enseñanza. Las posibilidades de uso destas tecnologías permiten otra mirada en los procedimientos y usos considerados habituales en el modelo presencial de enseñanza, trayendo consigo nuevas formas de comunicación y los nuevos significados para las prácticas educativas. En este sentido, estas tecnologías traen consigo la necesidad de algunos cambios que requerirán el desarrollo de nuevas habilidades y actitudes de los profesores y estudiantes (PAREDES, 2009). Un ejemplo de estas nuevas habilidades es una formación adecuada para la comunicación mediante redes sociales, blogs, EVA, y el uso de otros recursos tales como foros, wiki, mashup, etc. El uso de estos recursos puede incluso romper las barreras espaciales y posibilitar la gestión de tiempo de manera flexible, teniendo en cuenta que permite la creación de redes y el acercamiento entre los sujetos del proceso educativo que separa el espacio geográfico. 
El participante DE3, también con una actitud positiva ante las TIC, destaca los siguientes momentos de utilización: “Para preparar las clases y los comentarios (Word); para presentar contenidos (PowerPoint); para solicitar trabajos y actividades (plataformas como el Moodle); para resolver dudas (foros y salas de chat); y para evaluar (Moodle, Excel)". (Participante DE3)

Estos tipos de usos -en los tres momentos de la práctica docente- también son comunes por otros docentes, ya que existe el entendimiento de que las TIC pueden promover y enriquecer el proceso de aprendizaje, facilitando el intercambio de documentos, ideas, lo que permite la comunicación instantánea y habilita a los nuevos espacios interacción (PAREDES, 2013; SILVA, 2012). De este modo, se establece el proceso dialógico en la construcción del conocimiento.

El participante DM9 comenta que utiliza "la plataforma con instrucciones y materiales digitales para su uso durante la clase presencial. Y los recursos varían: audios, vídeos, lecturas y búsqueda de información”. (Participante DM9), es decir, en momentos preactivos e interactivos de la práctica docente. $\mathrm{Y}$ el sujeto DB8 dice que hace el uso de las TIC en especial en el momento interactivo para explorar los gráficos de funciones y figuras geométricas abordados en los contenidos de la materia, porque se puede “trabajar con software libre para explorar gráficos, imágenes y animaciones, incluyendo las técnicas en 3D”. (Participante DB8)

En estos comentarios, se puede notar la reconfiguración del proceso de enseñanza, dada la capacidad de las TIC para transformar las prácticas pedagógicas. Esto, sin embargo, dependerá del adecuado uso de los recursos en las actividades conjuntas llevadas a cabo por los docentes y estudiantes (DE PABLOS, 2010), sea en el modo presencial o a distancia.

En resumen, considerando los tres momentos de la práctica docente, se constató la realización de los siguientes usos de las TIC: a) en la preparación y ejecución de la clase, como apoyo técnico a la práctica, con el objetivo de explorar el potencial didáctico y comunicativo de los recursos (por medio de imágenes, vídeos, aplicaciones o simulaciones); b) para obtener información sobre el grupo de estudiantes, dialogar y 
conocer acerca de sus ideas y evaluar el trabajo, con Word, PowerPoint, Excel, Moodle, foros, blogs y salas de chat; c) para reflexionar sobre cómo fue el desarrollo de la asignatura; d) el uso de las redes sociales (Facebook, Twitter) y plataformas de Entornos Virtuales de Aprendizaje (EVA), para expandir el potencial comunicativo y de búsqueda e intercambio de información; y e) el uso de materiales digitales que se utilizaron durante las clases presenciales y el software libre para explorar gráficos, imágenes y animaciones, incluyendo las técnicas en 3D.

Así es posible entender que las TIC son elementos que pueden constituirse en un factor de motivación para el proceso de enseñanza y aprendizaje, pero esto está directamente relacionado con la posición del sujeto ante estas tecnologías así como con las estrategias didácticas adoptadas en el uso de tales recursos tecnológicos. Sin embargo, la motivación se deriva no sólo de la utilización de las TIC, sino de todo el proceso educativo, y también de la reconfiguración del proceso de enseñanzaaprendizaje (con el apoyo de estos recursos tecnológicos). Por lo tanto, la motivación de los sujetos de la investigación también tiene su fundamento ya en la planificación de un curso, en la posibilidad de la extensión y la variación de las acciones didácticas, en las nuevas formas de comunicación entre docentes y estudiantes, en las estructuras que ofrecen las instituciones educativas (que en principio pueden constituirse "un reto", dependiendo de la capacidad del sujeto para trabajar con las TIC), y también en el desarrollo de nuevas modalidades de enseñanza, como la educación a distancia.

\section{Conclusiones}

Los resultados de este estudio exploratorio presentan las percepciones de los docentes acerca de sus prácticas pedagógicas con las TIC, y esta aproximación tiene la finalidad de explorar la posible relación entre estas prácticas y los elementos que influyen en la postura personal de los docentes. Por el tipo de respuestas que dan los participantes, en este estudio no se han hecho presentes diferencias de género o por disciplina académica impartida apreciable. Los resultados muestran que las TIC ni siempre 
se aprovechan para dialogar con ideas establecidas o bien transformar la enseñanza. En unos casos, los usos desarrollados enmascaran prácticas tradicionales de enseñanza.

Ahora bien, los participantes en el estudio utilizan las TIC en diversos momentos de sus prácticas de docencia en la educación superior, tanto en los preactivos como en los interactivos y evaluativos de la enseñanza. Se señala que hay un equilibrio en las acciones durante esos tres momentos por parte de los docentes mexicanos y españoles, mientras que los docentes brasileños actúan con las TIC preferentemente en los momentos interactivos. Se pone en evidencia que no hay resistencias al utilizarlas en las prácticas docentes. Los docentes se dan cuenta de la incorporación de estes recursos tecnológicos en sus prácticas como algo positivo y "natural”, debido a la reconfiguración del proceso de enseñanza, como ya se mencionó.

Las TIC se utilizan en diversos grados. En lo que manifiestan algunos participantes se perciben prácticas docentes diversificadas favorecidas con las TIC. Por ejemplo, con estes recursos tecnologicos algunos docentes consiguen generar nuevos entornos que propician otras prácticas de enseñanza. Obviamente, los niveles de integración y los tipos de usos de los recursos varían de acuerdo a las necesidades, creencias y actitudes de cada sujeto (a lo que subyacen componentes motivacionales), pero parece estar claro que, independientemente de la estrategia didáctica de las TIC adoptada, hay una disposición a desarrollar una práctica docente mediadora, un factor que contribuye para que los estudiantes asuman su parte protagonista en el proceso educativo.

Con respecto a las condiciones en que se desarrollan estas prácticas, en las universidades se observa que se cumple el triángulo de infraestructura, conectividad y formación para el impulso de la utilización de las TIC, habitual en la enseñanza no universitaria. En este sentido, no se observa la carencia de competencias suficientes entre los profesores. $\mathrm{Y}$, por las respuestas de algunos docentes, se observa que las universidades han hecho una inversión en aproximar recursos institucionales y crear condiciones e infraestructuras suficientes, apostando por ejemplo por el software libre. Asimismo, llamamos la atención sobre la necesidad de entornos y espacios específicos para el proceso de formación de los docentes de la educación superior profesional, lo que 
ni siempre ocurre y, con ello, a menudo los docentes actúan solamente para hacer frente a los retos actuales en la enseñanza superior.

Ahora bien, tal y como pasa en otros niveles, parece que las instituciones de educación superior apuestan por la iniciativa singular de los docentes. Es una apuesta por individuos que puede ser insuficiente. Hace falta mejorar las condiciones institucionales, con políticas explícitas, una cultura institucional de innovación, organización suficiente para apoyarla y actores que lo hagan.

Entre los elementos que explican un nivel de aprovechamiento avanzado de las TIC por parte de los docentes -utilizar más veces, utilizar en diferentes momentos de la práctica docente, utilizar con variedad y para distintos propósitos-, se encuentran los siguientes procedimientos adoptados por esos profesores: repensar las formas de comunicación y el estatuto de los distintos actores en el desarrollo de la enseñanza aprovechando las posibilidades que brindan software y dispositivos-; repensar cada fase de la enseñanza -dando cabida a distintas formas de utilización de las TIC-; repensar el currículo -incluyendo otras problemáticas en la enseñanza-; romper espacio y tiempo académico -adoptando fórmulas de enseñanza a distancia-.

Sería esperable que con otras condiciones institucionales este aprovechamiento fuese más rico, mientras empiezan a moverse los fundamentos de las prácticas de la docencia en las instituciones de educación superior.

\section{Referencias}

ALAMINOS, Antonio \& CASTEJÓN, Juan Luis. Elaboración, análisis e interpretación de encuestas, cuestionarios y escalas de opinión. Alcoy: Editorial Marfil, 2006.

ALONSO-TAPIA, Jesús. Motives, expectancies and value-interests related to learning: The MEVA questionnaire. Psicothema, 17 (3), 404-411, 2005.

ALVES, Maria Palmira; MORGADO, José Carlos; LEMOS, Ana Raquel; CRUZ, Susana \& OLIVEIRA, Susana. Práticas Inovadoras no Ensino Superior. Braga: Instituto de Educação, Universidade do Minho, 2011. 
BARDIN, Laurence. Análise de conteúdo. Traducción de Luís Antero Reto y Augusto Pinheiro. São Paulo: Edições 70, 2011.

BRIJALDO-RODRÍGUEZ, Monica Llanda \& SABOGAL-MODERA, Maria Leonor. Trayectos de uso de TIC: Caso de la Universidad Javeriana. Magis, Revista Internacional de Investigación en Educación, 7 (15), 135-148, 2015.

CABERO, Julio. Nuevas tecnologías aplicadas a la educación. Madrid: McGraw Hill, 2006.

CHRISTENSEN, Clayton. Inovação na sala de aula: como a inovação disruptiva muda a forma de aprender. Traducción de Rodrigo Sardemberg. Porto Alegre: Bookman, 2012.

CORREA, José Miguel. Buenas prácticas con tecnología en los procesos de enseñanza y aprendizaje. En Correa, José Miguel (coord.). Políticas educativas TIC en el País Vasco y buenas prácticas de enseñanza y aprendizaje (pp. 39-51). Madrid: Ediciones Paraninfo, 2010.

CORREA, José Miguel; FERNÁNDEZ, Lorea; GUTIÉRREZ-CABELLO, Aingeru; LOSADA, Daniel \& OCHOA-AIZPURUA, Begoña. Formación del Profesorado, Tecnología Educativa e Identidad Docente Digital. RELATEC - Revista Latinoamericana de Tecnología Educativa, 14 (1), 45-56, 2015.

COX, Margaret; PRESTON, Christina \& COX, Kate. What motivates teachers to use ICT? Ponencia presentada en el British Educational Research Association Annual Conference, University of Sussex at Brigthon, 1999. Disponível em:

<http://www.leeds.ac.uk/educol/documents/00001329.htm>. Acesso: 20 mar. 2019.

DE PABLOS, Juan. Potenciación del trabajo del estudiante universitario mediante los usos de las tecnologías. En Paredes, Joaquín \& Herrán, Agustín (coords.). Cómo enseñar en el aula universitaria (pp. 173-183). Madrid: Pirámide, 2010.

FIGUEIREDO, António . Inovar em Educação, Educar para a Inovação. En Fernandes, D. (org.). Avaliação em Educação: Olhares Sobre uma Prática Social Incontornável (pp. 1328). Pinhais: Editora Melo, 2011.

GALLEGO, Maria Jesús. Profesorado, innovación y TIC en el currículo. En Cebrián, Manuel (coord.). Tecnologías de la Información y Comunicación para la formación de docentes (pp. 159-170). Madrid: Pirámide, 2005.

GARCÍA, Francisco. Motivación del profesorado universitario para el uso de las Tecnologías de la Información y la Comunicación (TIC) en el acto didáctico. Anuario de Pedagogía - Informe Final, Universidad de Zaragoza, 4, 165-196, 2002.

GIL, Antonio Carlos. Métodos e Técnicas de Pesquisa Social. São Paulo: Atlas, 1999. 
GISBERT, Merced, CABERO, Julio \& LLORENTE, Maria Cejudo. El papel del profesor y el estudiante en los entornos tecnológicos de formación. En Cabero, Julio. (coord.). Tecnología educativa (pp. 263-280). Madrid: McGraw Hill, 2007.

GONZÁLES, Mercedes. Las TIC como factor de innovación y mejora de la calidad de la enseñanza. En Cabero, Julio (coord.). Tecnología Educativa (pp. 219-232). Madrid: McGraw Hill, 2007.

HENDRIKS, Paul. Why share knowledge? The influence of ICT on the motivation for knowledge sharing. Knowledge and Process Management, 6 (2), 91-100, 1999.

KARSENTI, Thierry \& LIRA, Maria Lourdes. La importancia de la motivación y las habilidades computacionales de los futuros profesores en el uso de las TIC. Revista Iberoamericana de Educación Superior, 2 (3), 116-129, 2011.

MARTíN-CRESPO, Maria Cristina \& SALAMANCA, Ana Belén. El muestreo en la investigación cualitativa. NURE Investigación, 2007. Disponível em:<http://www.nureinvestigacion.es/OJS/index.php/nure/article/view/340>. Acesso: 12 mar. 2019.

MARTÍNEZ, Asunción \& CORREA, José Miguel. Innovación y cambio fuera y dentro de la escuela. En Correa, José Miguel (coord.). Políticas educativas TIC en el País Vasco y buenas prácticas de enseñanza y aprendizaje (pp. 29-38). Madrid: Ediciones Paraninfo, 2010.

MARTÍNEZ, Jaume. Pero ¿Qué es la innovación educativa? Cuadernos de Pedagogía, enero/2008, 375, 78-82, 2008.

MELARÉ, Daniela; NEVES, Cláudia; SEABRA, Filipa; MOREIRA, José Antonio \& HENRIQUES, Susana. Educação e Tecnologias: reflexão, inovação e práticas. Lisboa: Universidade Aberta, 2011.

MONTERO, Maria Lourdes \& GEWERC, Adriana. De la innovación deseada a la innovación posible. Escuelas alteradas por las TIC. Profesorado, 14 (1), 303-318, 2010. Disponível em: <http://www.ugr.es/local/recfpro/rev141ART16.pdf>. Acesso: 24 de mar. 2019.

MORAN, José Manoel. Formação de educadores inovadores para uma nova escola. TV ESCOLA - Série Salto para o Futuro - Educação Digital e tecnologias da informação e comunicação. Secretaria de Educação a Distância, Ministério da Educação do Brasil, Programa 3, Año XVIII - Boletín 18, 40-48.

OROZCO, Guillermo. ¿Podemos ser más creativos al pensar sobre cómo adoptar generalizadamente la innovación tecnológica en la educación? Una propuesta desde la comunicación. Matrizes, octubre/2007, 1, 209-216, 2007. 
PAREDES, Joaquín. La renovación pedagógica, más allá de las TIC en la universidad. Una opción personal. Matices del Posgrado Aragón - UNAM, año 8, enero-abril, 20, 134-146, 2013.

PAREDES, Joaquín. Innovación en los procesos de educación a lo largo de la vida. En Paredes, Joaquín \& Herrán, Agustín (coords.). La práctica de la innovación educativa (pp. 207-234). Madrid: Editorial Síntesis, 2009.

PAREDES, Joaquín \& ARRUDA, Rogério. La motivación del uso de las TIC en la formación de profesorado en Educación Ambiental. Ciência \& Educação, 18 (2), 353-368, 2012.

PRATA-LINHARES, Martha \& GAETA, Maria Cecília Damas. University Teachers Professional Development: Brazilian Context and Experiences. En Flores, M. A. \& Al Barwani, T. (orgs.). Redefining Teacher Education for the Post -2015- Era: Global Challenges and Best Practices (pp. 1-15). Hauppauge: Nova Science Publishers, 2016.

ROGERS, Everett. Diffusion of innovations. (3 ed.). New York: The Free Press, 1983.

SALINAS, Jesús. Innovación educativa y TIC en el ámbito universitario: Entornos institucionales, sociales y personales de aprendizaje. Ponencia presentada en el II Congreso Internacional de Educación a Distancia y TIC, Lima (Peru), 21-23 de octubre de 2009.

SANCHO, Juana Maria \& ALONSO, Cristina. La fugacidad de las políticas, la inercia de las prácticas. La educación y las tecnologías de la información y la comunicación. Barcelona: Octaedro, 2012.

SANCHO-GIL, Juana Maria. Em buscas de respostas para as necessidades educacionais da sociedade atual. Uma perspectiva multidisciplinar da tecnologia. Revista Linhas, Florianópolis, v. 14, n. 27, jul./dez. 2013. p. 09-44.

SANCHO, Juana Maria; BOSCO, Alejandra; ALONSO, Cristina \& SÁNCHEZ, Joan Anton. (2015). Formación del profesorado en Tecnología Educativa: de cómo las realidades generan los mitos. RELATEC - Revista Latinoamericana de Tecnología Educativa, 14 (1), 1730, 2015.

SILVA, Marco. Formação de professores para docência online. São Paulo: Edições Loyola, 2012.

SOARES-LEITE, Werlayne Stuart. \& NASCIMENTO-RIBEIRO, Carlos Augusto. A inclusão das TICs na Educação brasileira: problemas e desafios. Magis, Revista Internacional de Investigación en Educación, 5 (10), 173-187, 2012. 
TEJADA, José. Innovación didáctica y formación del profesorado. En Herrán, Agustín \& Paredes, Joaquín (coords.). Didáctica General. La práctica de la enseñanza en Educación Infantil, Primaria y Secundaria (pp. 311-332). Madrid: McGraw Hill, 2008.

TEJEDOR, Francisco Javier; GARCÍA-VALCÁRCEL, Ana; PRADA, Sagrario. Medida de actitudes del profesorado universitario hacia la integración de las TIC. Comunicar, 33, 115124, 2009.

YIN, Robert Kenneth. Case Study Research: Design and Methods. Thousand Oaks, CA: Sage Publications, 2014.

Recebido em: 30/04/2019 Aprovado em: 10/05/2019

Universidade do Estado de Santa Catarina - UDESC Programa de Pós-Graduação em Educação - PPGE Revista Linhas

Volume 20 - Número 43 - Ano 2019 revistalinhas@gmail.com 